
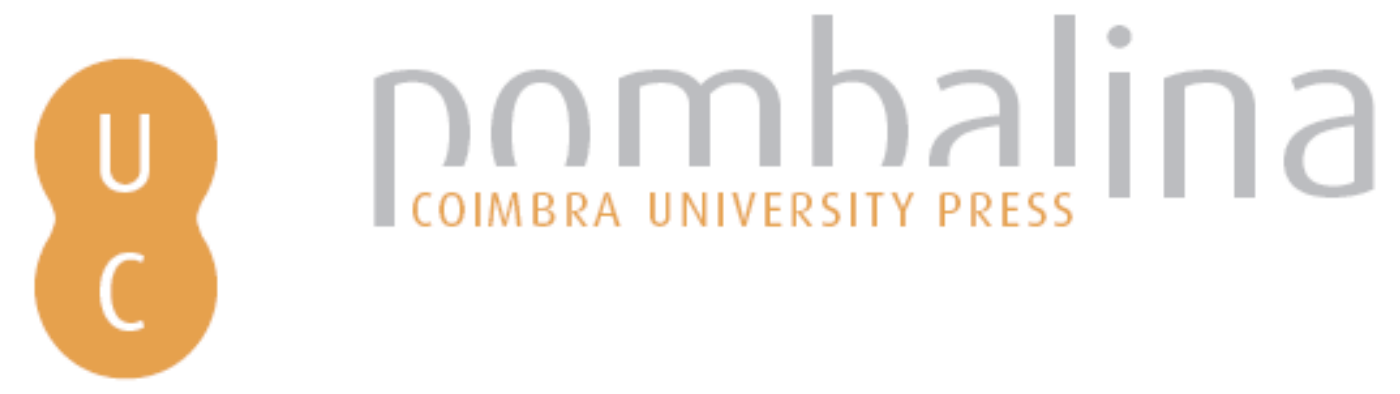

\title{
A relevância do De re aedificatoria na herança disciplinar da arquitetura clássica em Portugal: a influência da obra escrita de Alberti
}

\author{
Autor(es): $\quad$ Krüger, Mário \\ Publicado por: Imprensa da Universidade de Coimbra \\ URL \\ persistente: URI:http://hdl.handle.net/10316.2/36685 \\ DOI: $\quad$ DOI:http://dx.doi.org/10.14195/978-989-26-1015-3_23 \\ Accessed : $\quad$ 26-Apr-2023 13:34:57
}

A navegação consulta e descarregamento dos títulos inseridos nas Bibliotecas Digitais UC Digitalis, UC Pombalina e UC Impactum, pressupõem a aceitação plena e sem reservas dos Termos e Condições de Uso destas Bibliotecas Digitais, disponíveis em https://digitalis.uc.pt/pt-pt/termos.

Conforme exposto nos referidos Termos e Condições de Uso, o descarregamento de títulos de acesso restrito requer uma licença válida de autorização devendo o utilizador aceder ao(s) documento(s) a partir de um endereço de IP da instituição detentora da supramencionada licença.

Ao utilizador é apenas permitido o descarregamento para uso pessoal, pelo que o emprego do(s) título(s) descarregado(s) para outro fim, designadamente comercial, carece de autorização do respetivo autor ou editor da obra.

Na medida em que todas as obras da UC Digitalis se encontram protegidas pelo Código do Direito de Autor e Direitos Conexos e demais legislação aplicável, toda a cópia, parcial ou total, deste documento, nos casos em que é legalmente admitida, deverá conter ou fazer-se acompanhar por este aviso.

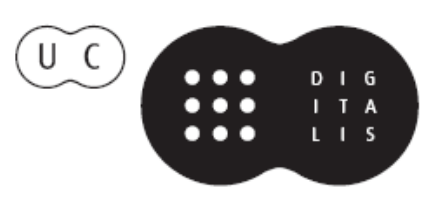


IMPRENSA DA

UNIVERSIDADE

DE COIMBRA

COIMBRA

UNIVERSITY

PRESS

\section{NA GÉNESE DAS RACIONALIDADES MODERNAS II}

Em torno de Alberti e do Humanismo

MÁRIO KRÜGER et alii

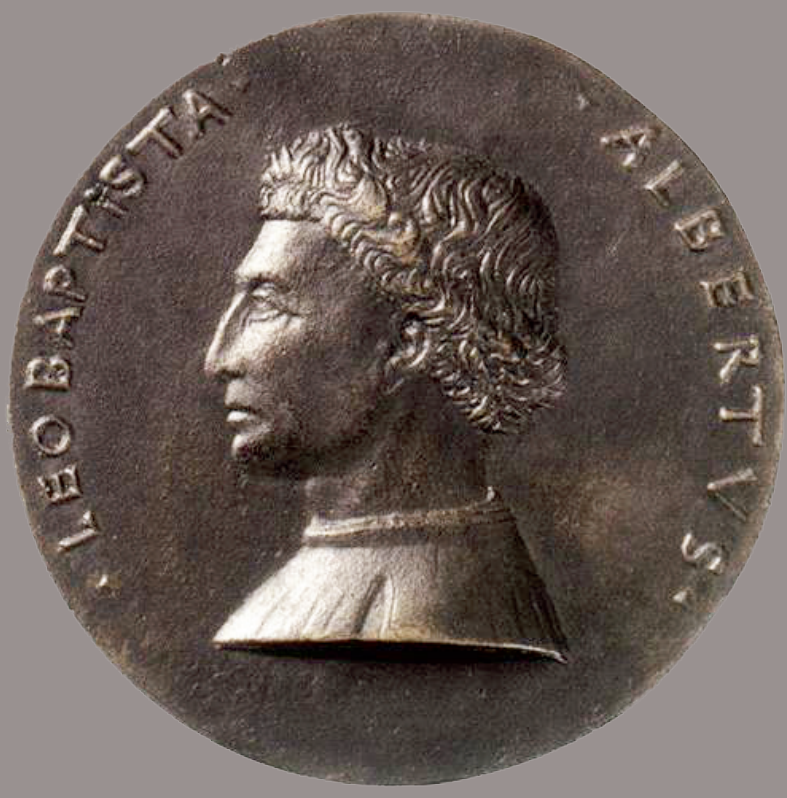


A RELEVÂNCIA DO DE RE AEDIFICATORIA NA HERANÇA DISCIPLINAR DA ARQUITETURA CLÁSSICA EM PORTUGA L :

\section{A INFLUÊCIA DA OBRA ESCRITA DE ALBERTI}

Mário Krüger

\section{Resumo}

Conhecido pelos seus contemporâneos por ter introduzido, de forma inovadora, a modernidade em arquitetura pela elaboração do tratado De re aedificatoria, a obra escrita de Leon Battista Alberti teve, no entanto, uma contingente receção em território nacional. Com efeito, a tradução em língua portuguesa por André de Resende, eventualmente elaborada em meados do séc. XVI, apesar de algumas referências coevas sugerirem a sua existência, nunca foi encontrada, nem sequer foi escrutinado qualquer fragmento da mesma que pudesse dar, de forma fidedigna, um testemunho documental.

No meio destas incertezas, uma certeza, o tratado é publicado em Castelhano em 1582 com tradução assistida por Francisco Lozano e parecer favorável de Juan de Herrera dado em 1578. Assim, face à periodização da receção ao tratado de Alberti no mundo ocidental, desde a editio princeps até aos dias de hoje, caracterizada pelos horizontes de espera encomiásticos, de reflexão crítica e de revisão em evolução, podemos dizer que a presumível tradução de Mestre Resende configura um "horizonte de perda", em termos da evolução da compreensão da arquitetura em Portugal nos últimos cinco séculos, principalmente pela ausência de um acolhimento explícito 
àquela obra e que a privou de um discurso comentador nas fases iniciais da sua receção.

Leon Battista Alberti; De re aedificatoria; Primeiras edições da obra escrita; Arquitetura Clássica; Portugal.

\section{Résumé}

Connu par ses contemporains pour avoir introduit, de manière innovatrice, l'architecture moderne dans la composition du traité De re aedificatoria, l'œuvre écrite de Leon Battista Alberti avait toutefois une réception cachée dans le pays.

En effet, la traduction en portugais par André de Resende, épisodiquement rédigé par le milieu du siècle XVI, bien que certaines références contemporaines suggèrent son existence, n'a jamais été retrouvé, ni a été examiné aucun fragment de ce que pourrait donner un documentaire témoin fiable.

Au milieu de ces incertitudes, une certitude, le traité est publié en espagnol en 1582 avec traduction assistée par Francisco Lozano et l'assentiment donné par Juan de Herrera en 1578.

Ainsi, étant donné le calendrier de la réception du traité d'Alberti dans le monde occidental, depuis l'editio princeps jusqu'à aujourd'hui, caractérisé par des horizons d'attente panégyrique, de réflexion critique et de révision en cours, nous pouvons dire que la traduction alléguée de Maître Resende configure un "horizon de perte" en termes de compréhension de l'évolution de l'architecture au Portugal au cours des cinq derniers siècles, surtout en l'absence d'une critique explicite à ce travail et qui le privait d'un texte commentateur dans les premiers stades de sa réception. Leon Battista Alberti; De re aedificatoria; Les Premières éditions de l'œuvre écrite; L'architecture Classique; Portugal.

\section{Abstract :}

Known by his contemporaries for introducing, in an innovative way, modernity in architecture by writing the treatise De re aedifi- 
catoria, the printed work of Leon Battista Alberti had, however, a contingent reception in the country.

Indeed, the translation into Portuguese by André Resende, possibly drawn up in the middle of the $\mathrm{XVI}^{\text {th }}$ century, despite some contemporary references suggested its existence, has never been found and up to now it was not scrutinized any fragment that could give, reliably, a documentary testimony.

In the midst of these uncertainties, a certainty, the treaty is published in Spanish in 1582 with assisted translation by Francisco Lozano and approval given by Juan de Herrera in 1578.

Thus, given the timeline of Alberti's treatise reception in the western world, from the editio princeps up to today, characterized not only by enthusiastic waiting horizons, but also by critical reflections under review, we can say that the alleged translation of Master Resende set up an "horizon's loss" in terms of understanding the evolution of architecture in Portugal in the last five centuries, notably for the lack of an explicit reception of Alberti's work that did not allowed a commentator speech in the early stages of its receipt.

Leon Battista Alberti; De re aedificatoria; First editions of written works; Classical Architecture; Portugal. 
No Colóquio Internacional "Na Gênese das Racionalidades Modernas - Em torno de Leon Battista Alberti" realizado de 4 a 8 de abril de 2011, na Escola de Arquitetura da UFMG, Belo Horizonte, apresentámos uma comunicação intitulada "A Tradução do De re aedificatoria de Leon Battista Alberti" estruturada em três partes: Receção e Antecedentes, Inteligibilidade e Eloquência e, por último, Termos Disciplinares.

$\mathrm{Na}$ notícia que fizemos no Colóquio "Na Génese das Racionalidades Modernas II - Em torno de Alberti e do Humanismo”, que agora se publica, retomamos a temática da receção inicial ao tratado de Alberti em Portugal, bem como das suas circunstâncias e da sua relevância na herança disciplinar da arquitetura clássica em Portugal.

Uma das questões, por enquanto irresolúveis, que abordámos no primeiro Colóquio refere-se à possível tradução do De re aedificatoria, elaborada por André de Resende (c.1495- 1573) no séc. XVI a mando de D. João III (1502 - 1557).

As indicações sobre esta encomenda e a eventual tradução do tratado de Alberti são escassas e, por vezes, contraditórias, pelo que iremos colocar algumas questões relacionadas com o contexto histórico em que se verificou esta receção.

Neste contexto, cabe destacar Schlosser ${ }^{620}$ que, baseando-se na Bibliotheca Lusitana ${ }^{621}$ de Diogo Barbosa Machado, sugere a existência de uma versão manuscrita em vernáculo, quando refere que "la traduction portugaise par André de Resende pour Jean III de Portugal est encore du XVe. Siècle”, para concluir que "cette traduction n'existe qu' en manuscrit; l'édition supposée de 1493 est une méprise". Também Mancini622 relata, equivocadamente, que "fra le molte opere dell'Alberti à la più conosciuta,

620 JULIUS VON SCHLOSSER, Die Kunstliteratur: ein Handbuch zur Quellenkunde der neueren Kunstgeschichte. Vienna: Anton Schroll; La Littérature artistique. Trad. fr. de J. Chavy, ed. de P. di P. Stathopoulos et alii e pref. de A. Chastel, Paris, Flammarion, 1996, p. 157.

621 DIOGO BARBOSA MACHADO, Bibliotheca Lusitana, Historia, Critica e Chronologica. Facsimile da ed. de Lisboa Occidental, Offic. de Antonio Isidoro da Fonseca, 1741-1759. Coimbra, Atlantida Editora, 1965-67, Volume I, s.V.

622 GIROLAMO MANCINI, Vita di Leon Battista Alberti. Fac-símile da edição de G. S. Sanzoni, Florença, 1882, publicada por Elibron Classics, Boston, Adamant Media Corporation, 2003, p. 393. 
fu tradotta in portoghese da Andrea Resendes (1493)". Analogamente Theuer ${ }^{623}$, na Introdução à edição alemã do De re aedificatoria, chega a assinalar a edição impressa de 1493 de Andrea Resendens.

Não é possível que André de Resende, nascido cerca de $1500^{624}$, tenha feito uma tradução do tratado de Alberti ainda no séc. XV, pelo que estas referências, para além de terem contribuído para o desenvolvimento da mitografia que acompanha a obra de Alberti em Portugal, não podem ser acolhidas.

Em 1534 Resende pronuncia a oração de sapiência, intitulada Oratio pro rostris, na Universidade de Coimbra para inaugurar o ano académico onde expressamente declara "Na verdade, é manifestação de sabedoria empregar, de preferência, um artista muito mais competente que os outros, quando se quer edificar uma obra incomparável”, o que sugere que este humanista tinha uma clara noção da importância da idoneidade autoral para se realizarem obras admiráveis, como sucede com a vasta produção literária e artística de Alberti.

Além disso, Resende ${ }^{625}$, nesta oração ainda elogia D. João III como sendo o "maior protector das letras e dos seus cultores", o que reforça a ideia de que a real encomenda para a tradução do tratado de Alberti se tenha verificado.

Também, Francisco de Monçon (?- 1575), capelão e pregador de D. João III, na obra Espejo del Principe Cristiano, publicada em 1571 afirma: "entre todos los Principes antiguos y modernos [...] el Rey don Iuan el tercero de Portugal de gloriosa memoria, que segun se dezian todos los maestros de pedreria, tenia gran destreza en saber hazer la traza de vnos palacios, y de vna fortaleza, y de qualquier obra tan perfectamente como si estuuiera hecha, y assy la mandaua añadir o mudar en la traça

623 MAX THEUER, "Zehn Bücher über die Baukunst”. In Deutsche übertragen, eingeleitet und mit Anmerkungen und Zeichnungen. Viena, H. Heller, 1912, p. LXIV.

624 FRANCISCO LEITÃo FERREIRA, Notícias da vida de André de Resende. Publicadas, anotadas e aditadas por A. B. Freire, 1916. Lisboa, Arquivo Histórico Português, 1732, pp. 6, 24 e 94, n. 3.

625 ANDRÉ DE RESENDE, Oratio pro rostris, 1534, Trad. port. de M. P. de Meneses, introdução e notas de A. Moreira de Sá. Lisboa, Instituto de Alta Cultura, 1956, p. 31. 
que los Architetos le dauan", o que sugere uma especial apetência real para a elaboração de traçados de obras de arquitetura a ponto de alterar significativamente os debuxos iniciais realizados pelos autores dos projetos e obras ${ }^{626}$.

Do mesmo modo, António de Castilho (c. 1525 - c. 1596), à época cronista do reino, na obra Vida del Rey Dom Joam III de Portugal, escrita em 1589627 declara que: “... florecerão em seu tempo outras artes apagadas que seu fauor espertou, como foi a Architectura a que o mesmo Rei se inclinou", o que também sugere e consolida as afinidades eletivas reais para com a arte edificatória.

É neste contexto que se dá a penetração de várias edições do De re

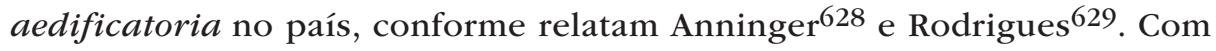
efeito, é de assinalar a presença das edições em latim editadas por Nicolai Laurentii Alamani (Florença - 1485), Berthold Rembolt (Paris - 1512) e Giacomo Cammerlander (Estrasburgo-1541), bem como as edições em vulgar de Pietro Lauro (Veneza - 1546), de Cosimo Bartoli (Veneza - 1565) e, para castelhano, de Francisco Lozano (Madrid - 1582).

É de notar, como fizemos na Introdução à edição de 2011 para português, que na receção global ao tratado de Alberti é possível identificar três horizontes de espera que apresentam traços em comum que designámos de encomiásticos, de reflexão crítica e de revisão em evolução.

626 FRANCISCO DE MONÇON, Libro primero del Espejo del principe christiano compuesto y nueuamente reuisto y muy e[m]mendado con nueua composicion y mucha addicion por el doctor Frãcisco de Monçon cuya leccion es muy prouechosa a todo genero de personas discretas aunque sean predicadores y cortesanos por las muchas y sabias sentencias y muy famosos y illustres exemplos que se ponen [...]. 1571, 2 ${ }^{\mathrm{a}}$ Ed. Lisboa, Antonio Gonçaluez.

627 ANTÓNIO De CASTILHO, Vida del Rey Dom Joam III de Portugal. Biblioteca Pública de Évora, 1589,Cód. CIII, 2-22.

628 ANNE ANNINGER, "Sebastiano Serlio's Books of Architecture and Their Influence on Portuguese Art in the Second Half of the Sixteen Century", Colóquio Sobre o Livro Antigo. Lisboa, 23-25 de maio. V Centenário do Livro Impresso em Portugal, 1487-1987. 1992. Lisboa, Biblioteca Nacional, 1988, p. 266.

629 ANA DUARTE RODRIGUES, "The circulation of art treatises in Portugal between the XV and the XVIII centuries: some methodological questions". In Tratados de Arte em Portugal, org. de A. D. Rodrigues-R. Moreira. Lisboa, Scribe, 2012, pp. $21-42$. 
O primeiro está relacionado com os encómios das gerações que primeiramente fizeram a sua receção, como sucede nas exegeses de Poliziano, Landino e Vasari. Neste caso, verificou-se uma identificação de admiração, onde o autor surge como herói, como um modelo a seguir, pela exemplaridade da sua obra. Este horizonte vai desde a publicação da editio princeps, em Florença em 1585, até à edição em castelhano, editada em Madrid em 1582.

Como podemos constatar, as citações que anteriormente fizemos de André de Resende, de Francisco Monçon e de António de Castilho coincidem com a última fase deste horizonte, onde a obra de Alberti é altamente valorizada, não só pela sistematização que faz da arte edificatória, praticamente intacta desde o tratado de Vitrúvio, como pela inovação que introduz ao fazer da arquitetura, no dizer de Leonardo da Vinci, como uma coisa mental.

Por outras palavras, o contexto no qual a presumível tradução de Resende poderia ter ocorrido era favorável à edição do tratado de Alberti em vernáculo.

No entanto, esta hipótese necessita de ser confirmada com provas documentais dado que não foi encontrado, até hoje, sequer algum fragmento desta possível tradução. Com efeito, Resende, no Prefácio da sua "História da Antiguidade da cidade de Évora", redigido em dezembro de 1552, para justificar a falta de tempo para prestar outros serviços à vereação, refere que andava "todo ocupado em um livro de arquitetura per mandado de El-Rei, Nosso Senhor630", mas não a fazer necessariamente a tradução do De re aedificatoria. Além disso, no seu testamento, datado de 1 de dezembro de 1573, confirma o que anteriormente tinha afirmado naquele Prefácio: "Mando que os meus livros de São Frey Gil e d'Architectura, e todo os mais livros e epístolas, que tenho composto, e me tem scrpito de for a partes e letreiros, tudo fique ao meu dito herdeiro[o filho, Barnabé de Resende], e ele

630 ANDRÉ DE RESENDE "História da Antiguidade da cidade de Évora" in A. Resende, 1963, Obras Portuguesas. Lisboa, Livraria Sá da Costa Editora, pp. 1-69. 
tenha todo muito bem guardado, porque são muito proueitosos para a sua honra e minha memória"631.

Por último, o Cónego Gaspar Estaço (1625) da Colegiada de Guimarães, desde muito novo protegido pelo cardeal-infante D. Henrique, no "Tratado da linhagem dos Estaços”, discorrendo sobre Simão Estaço informa que o cardeal the escrevera uma carta em que "lhe mandava, e encomendava, $q$ como falecesse Mestre Resende natural d'Evora, lhe tirasse da sua livraria certos livros, que desejava haver, como Leo Baptista de Architectura, que ele traduzio en Portuguez por mandado d'el Rei, e outros"632, o que sugere que eventualmente a tradução se tenha, pelo menos, iniciado.

Estes indícios, por serem algo contraditórios, não permitem que se chegue a uma resolução segura desta questão que, na sua essência, se revela com elevado grau de indeterminação633.

Apesar desta incerteza, o tratado de Alberti era, muito provavelmente, conhecido desde longa data na corte portuguesa como é sugerido pela correspondência epistolar trocada entre Ângelo Poliziano (1454 - 1494) e D. João II (1455 - 1495), datada de 23 de outubro de 1491, e que indica uma especial ligação entre a Casa dos Medicis e a Casa de Avis. D. João II fecha a resposta a esta carta com uma recomendação sobre os três filhos do Chanceler-mor do reino, João Teixeira, que tiveram a "feliz sorte de poder beber no manancial das tuas letras alguma doutrina" 634 , o que sugere que os moços-fidalgos, que estavam sob a sua orientação tutelar, teriam, provavelmente, conhecimento da editio princeps do De re aedificatoria, publicada em 29 de dezembro de 1485, com uma saudação de Poliziano a Lourenço de Medicis.

631 FRANCISCO LEITÃO FERREIRA, op. cit., p. 135.

632 GASPAR ESTAÇO, “Trattado da linhagem dos Estaços, naturaes d'Evora ...”. Compilado conjuntamente com "Varias Antiguidades de Portugal". Página de rosto ornamentada. 52 pp., il..Texto em duas colunas, com notas marginais, 1625. Lisboa, Pedro Craesbeeck.

633 De acordo com Rafael Moreira a tradução do De re aedificatoria foi efetivamente realizada por André de Resende, apesar de as fontes citadas serem as mesmas. Cf. RAFAEL MOREIRA, "Alberti et Francisco de Melo, Renaissance Cartographique et Architecturale au Portugal”, Albertiana, 2014, Vol. XVII, pp. 23-51.

${ }^{634}$ Cf. FIDELINO DE FIGUEIREDO, "Angelo Poliziano e D. João II". In A Épica Portuguesa no Século XVI. Gaia, Edições Pátria, 1932, p. 50. 


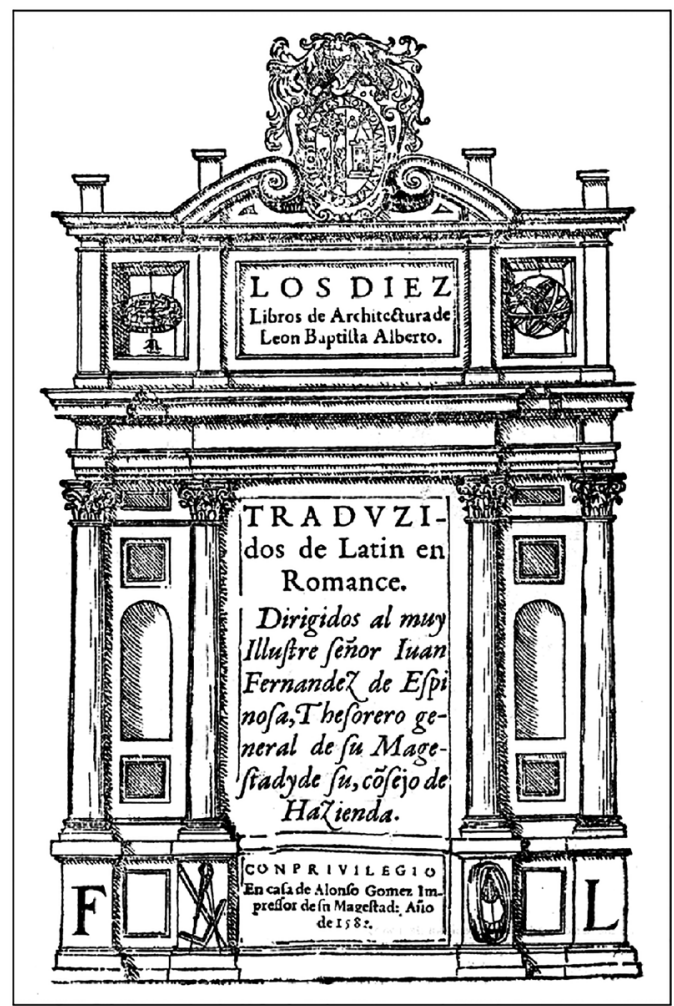

Fig. 1 - Frontispício de Los Diez Libros de Architectura de Leon Baptista Alberto traduzidos de Latin en Romance por Francisco Lozano, 1582 .

Com efeito, dos 54 estudantes portugueses que frequentaram o Studio Fiorentino 635 entre 1473 e 1503, encontravam-se os três filhos, Álvaro, Tristão e Luís do Chanceler João Teixeira, que seguiram as aulas de Poliziano, provavelmente entre 1488 e 1492, sobre Plínio, como atestam os registos de frequência destes moços-fidalgos no Studio, bem como o comentário daquele à obra deste autor romano: "Britannis quibusdam et Lusitanis, qui se Florentiam contulerant litterarum studio ${ }^{636}$.

635 O Studio Fiorentino, fundado em 1348 como um Studium Generale, foi reorganizado em 1473 sob a administração de Lourenço de Medicis tornando-se, a partir de então, o foco da política cultural da República Florentina.

636 Cf. RITA BISCETTI, "La gloria dei portoghesi: ancora sull'epistola do Poliziano a D. João II", in Humanismo português na época dos descobrimentos: actas / congresso inter- 
Destes irmãos, o que se destacou na educação clássica de D. João III, foi Luís Teixeira, nomeado precetor do príncipe quando este tinha 17 anos e transmitido conhecimentos sobre as Epístolas de Ovídio, bem como sobre os livros de Plínio e Tito Lívio e, ainda, noções de direito romano a partir das Instituta ${ }^{637}$. É provável que Luís Teixeira tenha dado a conhecer ao príncipe, após a sua estadia em Florença e Bolonha, obras dos humanistas do renascimento italiano, nomeadamente das que tomou conhecimento no Studio Fiorentino.

No meio destas incertezas, o que é certo é que a primeira publicação impressa do tratado de Alberti na Península Ibérica viu a estampa em 1582 em Madrid, aparentemente traduzida para castelhano por Francisco Lozano, com o título Los Diez Libros de Architectura de Leon Baptista Alberto traduzidos de Latin en Romance e impressa por Alonso Gomez 638 .

Se bem que a autoria daquela tradução para castelhano do tratado de Alberti seja, geralmente, atribuída a Francisco Lozano, um mestre de obras de albañilería, sobre o qual muito pouco se sabe, a rigor, a mesma pode ser originalmente imputada ao cosmógrafo real Rodrigo Zamorano, autor da versão espanhola dos seis primeiros livros da Geometria de Euclides.

Morales ${ }^{639}$ argumenta que a edição não foi do agrado de Zamorano "porquanto se realizó partiendo de borradores cuyos textos debían haber sido pulidos antes de enviarse a la imprenta [... e] que su insatisfacción radicava más en la falta de una revisón del texto, previa a su traslado a

nacional, Coimbra, 1991. Coimbra, Centro de Estudos Clássicos e Humanísticos, 1993, p. 295; ARMANDO F. VERDE, Lo Studio Fiorentino 1473-1503. Ricerche e Documenti. Pistoia, Memorie Domenicane, vol.III, 1977, p. XXIII e p. 5; VINCENZO FERA, Una ignota Expositio Suetoni dei Poliziano. Messina, Centro di Studi Umanistici, 1983, p. 19.

637 Cf. ANA ISABel BUesCU, D. João III. Rio de Mouro, Círculo de Leitores, 2005, p. 33 .

638 LEON BATTISTA ALBERTI, De Re Aedificatoria ó Los Diez Libros de Arquitetura. Madrid, Alonso Gomez, 1582. Fac-símiles da tradução para castelhano do De re aedificatoria assistida por F. Lozano. Oviedo, Colegios Oficiales de Aparejadores y Arquitetos Técnicos, 1975. Valência, Albatroz Ediciones, 1977.

639 ALFREDO J. MORALES, "El cosmógrafo Rodrigo Zamorano, Traductor de Alberti al español”, Annali di Architettura, 7, 1995, p. 141. 
las prensas, que a la circunstancia de figurar outra persona, evidentemente Francisco Lozano, como autor de la traducción"640.

Além disso, não é provável que Lozano, um albañil com atividade na cidade de Madrid, tivesse um domínio seguro da língua latina para fazer uma abalizada tradução do tratado de Alberti.

$\mathrm{Na}$ verdade, se compararmos os títulos dos livros da editio princeps (ep), bem como da tradução para vulgar de Cosimo Bartoli (CB), ambos referidos como textos de origem, com a hipotética tradução elaborada por Lozano (FL), notam-se discrepâncias assinaláveis.

Com efeito, os títulos de alguns livros da edição de Lozano não coincidem com os restantes, como pode ser seguidamente verificado:

Livro I ep Leonis Baptistae Alberti De re aedificatoria Liber Primus Incipit. Lineamenta.

CB Della Architettura di Leon Batista Alberti. Libro Primo.

FL Libro Primero de los Lineamentos de Leon Baptista Alberto.

Livro II ep Leonis Baptistae Alberti De re aedificatoria Liber Secundus Incipit. Materia.

CB Della Architettura di Leon Batista Alberti. Libro Secondo. Nel Cale Si Trata De Legnami.

FL Libro Segundo de Leon Baptista Alberto de la Materia.

Livro VII ep Leonis Baptistae Alberti De re aedificatoria Liber Septimus Qui Sacrorum Ornamentum Inscribitur.

CB Della Architettura di Leon Batista Alberti. Libro Settimo. Delli Ornamenti de Tempii Sacri.

FL Libro Septimo de Leon Baptista Alberto, De La Arte de Edificar.

640 O tradutor do tratado de Alberti para Castelhano foi o "Catedrático de Cosmografia en la Casa de la Contratación de las Indias en Sevilla, Rodrigo Zamorano" (ver Morales, Ibidem; MIGUEL ÁNGEL, ARAMBURU-ZABALA HIGUERA, CELESTINA LOSADA VAREA - ANA CAgIGAS ABERASTURI, Biografia de Juan de Herrera. 2003. Santander, Fundación Obra Pía Juan de Herrera. 
Assim, nos Livros I e II Lozano omite do título a tradução de De re aedificatoria ou de Della Architettura e no Livro VII, inclui o título De La Arte de Edificar, mas omite a tradução de Qui Sacrorum Ornamentum Inscribitur ou de Delli Ornamenti de Tempii Sacri, o que sugere que, provavelmente, Lozano serviu-se de outra fonte que não a da editio princeps, ou mesmo da edição para vulgar de Cosimo Bartoli.

O estudo de Monllor ${ }^{641}$ sobre o vocabulário técnico da edição de Lozano faz um levantamento dos termos que foram usados pela primeira vez em castelhano e que podem ser cotejados com a literatura coeva em língua portuguesa.

Os termos comuns ao castelhano e ao português e passíveis de serem identificados na edição de Lozano são: amphitheatro, area, boveda, çapata, estacada, pulimento e sobrado, o que poderia sugerir alguma contaminação de lusismos técnicos na edição de Lozano. No entanto, area, çapata e sobrado entram no vocabulário português no séc. XIII ${ }^{642}$; boveda no léxico de ambas as línguas no mesmo período 643 e amphitheatro, estacada e pulimento somente fazem parte do léxico em vernáculo, respetivamente, nos sécs. XV e XVII ${ }^{644}$, o que descarta a possibilidade de Lozano ter utilizado, eventualmente, estes termos a partir da hipotética tradução de Resende.

Na dedicatória que Lozano faz "Al Muy Illustre Señor Iuan Fernandez de Espinosa, Thesorero general de su Magestad y de su Consejo de Hacienda” informa que "asisti a la traducion del, con tanta fidelidad, quanta me fue possible, y traduzidos procure imprimirle" 645 , o que significa que este

${ }^{641}$ ROSA MARÍA GONZÁLEZ MONLLOR, "Notas Sobre la Formación del Léxico Técnico de la Arquitetura y de la Construcción en Español: El Caso de los Diez Libros de Arquitetura de Leon Battista Alberti", in Y. A. Santana ed. e R. M. Q. Domínguez coord., Homenaje a Alfonso Armas Ayala, Tomo I. Las Palmas, Ediciones del Cabildo de Gran Canaria, 2000, pp. 437-452.

642 Cf. ANTÔNIO HOUAISS - MAURO DE SALLES VILLAR, Dicionário Houaiss da Língua Portuguesa. Lisboa, Círculo de Leitores, 2002, p. 364; p. 1611; p. 3351.

643 ROSA MARÍA GONZÁlEZ MONLLOR, op. cit., pp. 442.

644 Cf. ANTÔNIO HOUAISS - MAURO DE SALLES VILLAR, op. cit., p. 218; p. 2916.

645 FRANCISCO LOZANO, De Re Aedificatoria ó Los Diez Libros de Arquitetura de Leon Baptista Alberto, traduzido de Latim em Romance. 1582. Madrid, Alonso Gómez. Fac-símiles da tradução da editio princeps de Leon Battista Alberti. Oviedo, Colegios Oficiales de Aparejadores y Arquitetos Técnicos, 1975; Valência, Albatroz Ediciones, 1977. 
não fez a tradução mas que assistiu, isto é, auxilou na sua feitura, o que confirma a hipótese de Morales ${ }^{646}$.

É também de assinalar que Juan de Herrera (1527 - 1598), arquiteto real ao serviço de Filipe I de Portugal e II de Espanha, dá parecer favorável, datado de 4 de agosto de 1578, para que "los diez libros de Leon Baptista Alberto" sejam impressos em castelhano e que a autorização real, para a impressão do tratado, seja dada a Francisco Lozano, "maestro de obras vezino de la villa de Madrid", a 17 de outubro desse mesmo ano ${ }^{647}$. Tal prazo tão dilatado entre a data da autorização e a sua efetiva publicação em 1582 não era comum nas edições da época em castelhano.

Assinale-se que de 1580 a 1640 as coroas de Portugal e de Espanha, sob o domínio dos Austrias, conviviam em união dinástica tendo, nesse período, muitas obras da biblioteca da dinastia de Avis migrado para o país vizinho.

O descaminho de livros neste período é uma constante da condição da cultura em Portugal, como relata Diogo do Couto 648 ao informar que o autor dos Lusíadas "foi escrevendo muito em um livro, que intitulava Parnaso de Luís de Camões, livro de muita erudição, doutrina e filosofia, o qual lhe juntaram (roubaram). E nunca pude saber, no reino dele, por muito que inquiri. E foi furto notável." A própria Década da Ásia foi subtraída a Diogo do Couto tendo este feito um resumo, que só seria editado a título póstumo em 1673.

Além disso, o rei e cardeal D. Henrique (1512 - 1580) tinha solicitado, como vimos, a Gaspar Estaço o de Architectura de Alberti, o que significa que esta obra ainda chegou a fazer, muito possivelmente, parte do acervo daquela biblioteca real.

É de notar que Juan de Herrera (1530 - 1597), após a sua permanência em Portugal ${ }^{649}$, funda a Academia de Matemáticas de Madrid podendo-se

646 ALFREDO J. MORALES, op. cit..

647 Cf. FRANCISCO LOZANO, Ibidem,

648 Diogo Do COUTO, Da Ásia. Década Oitava. Lisboa, Na Régia Oficina Tipográfica, 1786, cap. 28 , p. 233.

649 O modelo de relação entre o arquiteto e o rei, que se implantou em Espanha neste período, solicitava um diálogo para o qual o tratado de Alberti daria uma indispensável contribuição dado que, o primeiro, necessitava de ser versado em matemáticas e nos conhecimento da Antiguidade e, o segundo, de estar ao corrente das novas disposições da 
encontrar no seu espólio pessoal, as seguintes obras de Alberti, sejam estas impressas ou manuscritas ${ }^{650}$ :

Los diez libros de architetura de léon bautista alberti florentino en latin; Arquitetura de léon bautista en toscano;

Los diez libros de arquitetura de léon bautista en rromanze;

Léon bautista sobre la arquitetura manoescrito en rromance.

Neste conjunto, sobressai a última obra que poderá ser identificada com o eventual manuscrito de Resende, dado que foi escrito em romance e concorda com a nomeação dada por Estaço ${ }^{651}$ - Leo Baptista de Architectura - do livro que "el-rei desejava haver".

Também no espólio de Francisco de Mora (c.1553 - 1610), o arquiteto que substitui Juan de Herrera, após o seu falecimento, na obra do Monasterio del Escorial, podemos verificar que estavam listadas as seguintes obras de Alberti652:

Arquitetura de leon bautista alberti en toscano 6 reales;

Opusculos de leon bautista alberti 5 reales;

Leon bautista alberti de azcitoria 4 reales;

Leon bautista alberti de arquitetura 4 reales;

Seys querpos chicos de arquitetura de leon bautista 4 reales.

Destas obras destaca-se a última, também um manuscrito, relativa a seys querpos chicos, ou seja seis livros, eventualmente identificáveis com o que restou da tradução de Resende e que passou da biblioteca de Juan Herrera para a de Francisco de Mora.

arte edificatória. Cf. CATHERINE WILKINSON-ZERNER, Juan de Herrera: Arquiteto de Filipe II, 1996, Trad. de Isabel Balsinde. Madrid, Ediciones Akal.

650 Cf. AGUSTÍN RUIZ DE ARCAUTE, Juan de Herrera. Edição de 1977. Madrid, Instituto Juan de Herrera, Escuela Técnica Superior de Arquitetura, 1936, pp. 150-171.

651 GASPAR ESTAÇO, op. cit.

652 Cf. AGUSTÍN BUSTAMANTE - FERNANDO MARIAS, "La révolution classique: de Vitruve à l'Escurial", Revue de l'Art, 1987, Vol. 70, 1, pp. 307-318. 
Dos três agrupamentos de edições do tratado que são passíveis de serem assinalados, como vimos o primeiro vai desde a editio princeps de 1485, em latim, até à de 1582, em castelhano; o segundo que engloba as publicações, em inglês, de 1729 até à italiana, de 1847, e o terceiro, que se reporta ao espaço entre a publicação de 1912, em alemão, até à de 2010, em italiano, apresentam traços em comum que podemos designar, em função dos comentários elaborados em Krüger ${ }^{653}$, respetivamente, de encomiásticos, de reflexão crítica e de revisão em evolução.

Nesta receção a primeira exegese em Portugal favorável a Alberti é feita por Mateus do Couto-o-Velho, no Tractado De Architectura, datado de 1631, que assertivamente declara, entre o final do período encomiástico e o início do período de reflexão crítica: "o grande Leo Bapt. ${ }^{a}$ Alberto, a quem com razão podemos chamar cabeça de todos elles"654.

Este acolhimento tardio ao tratado de Alberti, que é tomado como modelo por Mateus do Couto-o-Velho para estruturar o seu Tractado De Architectura, mostra a difícil penetração que os conceitos e práticas sugeridas por Alberti tiveram inicialmente no país, onde predominava o domínio do mestre-construtor, oriundo das experiências dos estaleiros medievais.

Ainda em pleno período de reflexão crítica, Cirilo Wolkmar Machado ${ }^{655}$, nas reflexões sobre as inconveniências da Architectura, aparenta ter plena compreensão da atividade mental do arquiteto, chegando mesmo a lamentar como este tem sido desprezado em favor do mestre-construtor: "os melhores pensamentos de hum architecto são mentaes, expressos se fazem visíveis pelo dezenho. A obra que executa um mestre he palpável - e a ignorância que he cega reputa naturalmente por nada o que não vê e por tudo o que palpa e toca; daqui nasce que se gasta muito e com gosto no material quando apenas e com hum desgosto se dá alguma coisa

653 MÁRIO JÚLIO TEIXEIRA KRÜGER, Introdução. In LEON BATTISTA ALBERTI, Da Arte Edificatória, Lisboa, Fundação Calouste Gulbenkian, 2011, pp. 75 - 130.

654 MATHEUS DO COUTO - O - VELHO, Tractado De Architectura Que leo o Mestre, e Archit[ect]o Mattheus do Couto o velho No anno de 1631 [Manuscrito]. BNL, Res., Cod. 946.

655 CIRILO WOLKMAR MACHADO, Algumas reflexões sobre as inconveniências da Architectura escritas aos 21 de junho de 1793 aos 45 annos da m/vida. Manuscrito, 1793/ 1796 - 1808. Lisboa, Academia Nacional de Belas Artes. 
a quem faz o dezenho, que se preza muito o mestre e que se despreza assaz o architecto".

No entanto, é o próprio Cirilo ${ }^{656}$, que afirma, a propósito das molduras de "Alberti e Sérlio seus imitadores [de Vitrúvio] forão mesquinhos", o que sugere uma continuada e explícita censura a Alberti, resultante da difícil penetração que as ideias deste tiveram nesse período e no país.

Já na contemporaneidade, em pleno período de revisão em evolução da obra de Alberti, Álvaro Siza 657 ao referir-se à complementaridade dos saberes necessários aos arquitetos declara que “... não é possível dar resposta a uma necessidade social particular, que inclui e da qual dependem as outras: a Beleza. Essa é a primeira responsabilidade do arquiteto, nunca o capricho", o que significa um pleno reconhecimento e aceitação, ainda que de forma implícita, daquele autor do Renascimento pela centralidade que esta temática apresenta na sua produção literária e artística.

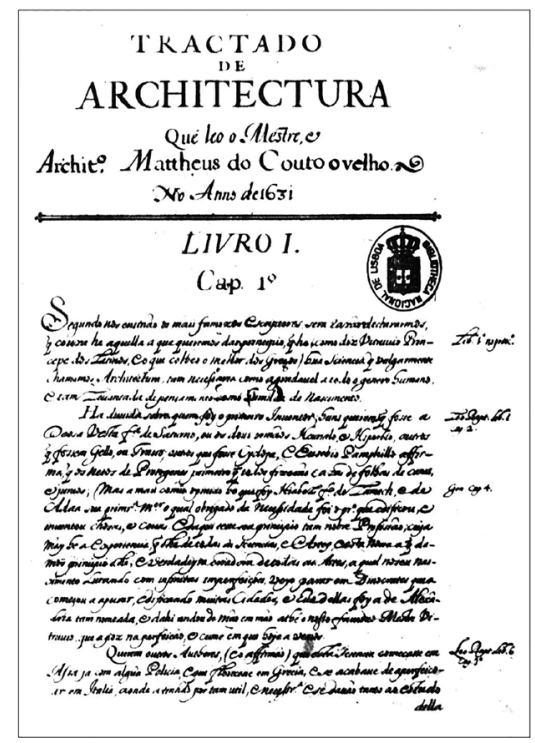

Fig. 2 - Frontispício do Tractado De Architectura de Mateus do Couto-oVelho, datado de 1631, mostrando duas anotações na margem do texto relativas a Leo Bapt., Livro I, cap. 2 e Livro VI, cap. 3.

656 CIRILO WOLKMAR MACHADO, op.cit., fl. 43.

657 ÁlVARO SIZA, Oração de Petição do Grau. In Doutoramento Honoris Causa de Álvaro Siza e Brian Scarllet, Coimbra, Universidade de Coimbra, 1997, p. 11. 
Uma notável exceção, que ocorre entre o período encomiástico e o início do período de reflexão crítica, é-nos dada por João Baptista Lavanha, no Livro Primeiro de Architectura Naval, Da Architectura e do Architecto Universal ${ }^{658}$ em que este se afirma como incondicional adepto das recomendações albertianas para a formação do arquiteto: "E para ser tal, qual nesta diffinição o forma Lião Baptista Alberti (cuja ella he) he necessario que dotado de agudo engenho, de conselho maduro, e de prudencia, seja muy estudioso, e ornado de singulares partes, das quaes serão as principaes, o Debuxo, e das Mathematicas, a Perspectiua, [a] Arithmetica, [a] Geometria, [a] Astronomia, e [a] Mechanica”659.

Esta integral adesão às ideias de Alberti sugere que a prática e a teoria da arquitetura naval estavam mais em consonância com a difusão do Renascimento para fora de Itália, do que com a atividade do mestre-construtor que ainda predominava no país, como parece sugerir Cirilo Volkmar Machado anos mais tarde.

Com efeito, o tratado de Alberti pode ser visto como muito próximo dos saberes necessários à arquitetura naval, dado que ao rematar o Prólogo Alberti afirma que existem "Livros acrescentados: o navio; relatório de custos; aritmética e geometria; os instrumentos que o arquiteto utiliza no seu trabalho" 660 .

Estes quatro livros perderam-se apesar de terem sido feitas referências no tratado ao primeiro e ao terceiro livros ${ }^{661}$. Alberti assume, consequentemente, que o arquiteto deve possuir conhecimentos de arquitetura naval, bem como de matemática para aplicações com finalidades práticas.

658 Cf. JOÃO DA GAMA PIMENTEL BARATA, O 'Livro Primeiro de Architectura Naval' de João Baptista Lavanha. Estudo e transcrição do mais notável manuscrito de construção naval portuguesa do século XVI e princípio do XVII, 1965, Ethnos, vol. IV, pp. 221-298.

659 JOÃO BAPTISTA LAVANHA, Livro Primeiro de Architectura Naval, Da Architectura $e$ do Architecto Universal, Cap. I, fl. 42, c. 1600, in JOÃO DA GAMA PIMENTEL BARATA, "O 'Livro Primeiro de Architectura Naval' de João Baptista Lavanha. Estudo e transcrição do mais notável manuscrito de construção naval portuguesa do século XVI e princípio do XVII", Ethnos, vol. IV, 1965.

660 LEON BATTISTA AlBERTI, Da Arte Edificatória. Trad. A. E. Santo, introd., notas e revisão disciplinar de M. J. T. Krüger, 2011. Lisboa, Fundação Calouste Gulbenkian.

661 JOÃO BAPTISTA LAVANHA, op. cit., Livro V, cap. 12; Livro III, cap. 2. 
Esta obra é também mencionada por Leonardo da Vinci nos seus livros de anotações, onde reporta: Vedi de navi di messer Battista e Frontino de acquedotti ${ }^{662}$, o que sugere a importância deste ramo do conhecimento na formação e prática do arquiteto.

Ao invés do que se verifica com outras línguas europeias, existem poucas obras, da vasta produção literária da obra de Alberti, que estejam traduzidas para a língua portuguesa, o que dificulta a inserção do tratado no quadro linguístico e epistemológico em que operamos desde o Quatrocentto 663 .

Podemos, no entanto, constatar a existência da comédia teatral Eufrosina (nome grego que designa uma das Graças ${ }^{664}$ ) de Jorge Ferreira de Vasconcelos, com $1^{\text {a }}$ edição em 1555, que se aproxima do romance de costumes sobre o amor, em ambiente Coimbrão, e que segue a estrutura compositiva da peça teatral Pbilodoxeos fabula (Amigo da Glória), c. 1424, de Alberti665.

A obra Philodoxeos ${ }^{666}$ fabula é uma comédia alegórica em que os seus principais protagonistas aspiram à conquista da sua amada. No desfecho, esta casa com Philodoxus, enquanto o seu rival Fortunius, surpreendido, será obrigado a casar com outra personagem. De acordo com Asensio 667 , que escreveu o prólogo para a edição de Eufrosina, Ferreira de Vasconcelos poderá ter retirado a sua estrutura organizativa a partir do texto de Alberti.

662 Apud PIETRO C. MARANI, "Leonardo e Leon Battista Alberti". In Leon Battista Alberti. Catalogo della mostra Palazzo Te, org. de J. Rykwert - A. Angel. Milão, Olivetti e Electa, 1996, p. 361.

663 Algumas obras de Alberti que se referem tanto aos diálogos, como à tratadística e aos Ludi têm sido, mais recentemente, editadas no Brasil, o que sugere que está em formação, desde 1970, de uma bibliografia de Alberti em língua portuguesa.

664 As Cárites, em latim Gratiae (Graças), são divindades da Beleza que moram no Olimpo na companhia das musas e são, geralmente, representadas por três irmãs que têm os nomes de Eufrósina, Talia e Aglaia. Atribui-se às Graças toda a espécie de influências nos trabalhos do espírito e nas obras de arte.

665 Cf. ANTÓNIO JOSÉ SARAIVA - ÓSCAR LOPES, História da Literatura Portuguesa. Porto, Porto Editora, 2000, pp. 385 - 389.

666 LEON BATTISTA ALBERTI, Pbilodoxeos fabula, 1977, ed. da primeira versão in Rinascimento, s.II, XVII.

667 EUGENIO ASENSIO, Comedia Eufrosina de Jorge Ferreira de Vasconcelos, "texto de la edicion principe de 1555 com las variantes de 1561 y 1566". Edição, prólogo e notas. Madrid, CSIC - Instituto Miguel de Cervantes, 1951, p. LXI. 
No estudo feito por Malkiel ${ }^{668}$ sobre La originalidad artistica de La Celestina, esta autora ao referir-se comparativamente ao texto de Vasconcelos com o Philodoxeos mostra que em ambos os escritos se nota a mesma motivação dramática, coerência de tema, personagens convicentes, desenvolvimento emocional progressivo, diálogos perspicazes e variações inéditas nas personagens principais como nas secundárias.

Mesmo nos diálogos que as diferentes personagens tecem entre si nota-se uma influência da peça de Alberti na composição da Eufrosina. Com efeito, ao tratar o tema da beleza nesta comédia, diz Andrade, criado de Zelótipo, ao seu amo: "Vi a senhora Eufrosina tam fermosa que nunca cuydey ver cousa daquella maneira ..."669, enquanto a mesma temática é abordada por Alberti de uma forma que lembra a definição de pulcritude dada no De re aedificatoria, onde Potentio descreve ao rival de Philodoxus a beleza de Doxia:

"Fortunius: E é bela?.

Potentio: De tamanha beleza e caráter que nada pode ser mais acrescentado ou desejado - tanto assim que penso que é mais bela que Vénus - ou, pelo menos, é muito parecida"670.

Na verdade, Alberti ${ }^{671}$ define no De re aedificatoria a beleza como a concinidade "em proporção exacta, de todas as partes no conjunto a que pertencem, de tal modo que nada possa ser adicionado ou subtraído, ou transformado sem que mereça reprovação"672.

668 MARÍA ROSA LIDA DE MALKIEL, La originalidad artistica de La Celestina, 1970, Buenos Aires, EUDEBA.

669 JORGE FERREIRA VASCONCElos, Eufrosina. Coimbra. Comédia Eufrósina. Adaptação de Silvina Pereira e Rosário Laureano Santos. Lisboa, Edições Colibri, 1998, Ato II, Cena 2.

670 LEON BATTISTA ALBERTI, Philodoxeos fabula, op. cit., s.II, XVII, Ato III

${ }^{671}$ LEON BATTISTA ALBERTI, Da Arte Edificatória. Op.cit., Livro IV, cap. 2.

672 Esta definição de beleza, se bem que em contextos diversos, já se encontra em Platão, bem como em Cícero; Cf. PLATÃO, Leyes. Trad. esp., intr. e notas de J. M. Pábon-M. Fernández, 2002. Galiano. Madrid, Alianza Editorial, V, 746c; MARCUS TUlliUS CíCERO, El Orador. Intr., trad. esp. e notas de E. S. Salor, 2011, Madrid, Alianza Editorial, III, 45. 
No Siglo de Oro da literatura espanhola, que vai da Gramática de Nebrija ${ }^{673}$ de 1492, até à morte de Calderón de la Barca em 1681, Francisco de Quevedo (1580-1645), um dos principais protagonistas desse período, comenta que "Esta comedia Eufrosina, que escrita en Portugués se lee sin nombre de autor, es tan elegante, tan docta, tan exemplar, que haze lisonja la duda que la atribuye a cualquier de los más doctos escritores de aquella nación. Muestra igualmente el talento y la modestia del que la compuso, pues se calló tanta gloria que oy apenas la conjetura halla sujeto capaz a quien poder atribuirla"674.

Semelhante destino também teve a comédia Philodoxeos fabula de Alberti visto que a sua autoria foi confundida pelo seu impressor Aldus Manutius, dada a maestria expressiva de Alberti para com a língua latina, como um trabalho do autor romano Lepidus ${ }^{675}$.

Tanto a comédia Eufrosina de Vasconcelos, como o De re aedificatoria de Alberti foram sujeitos ao crivo da Santa Inquisição a ponto de ser proibida a sua circulação e impressão na península Ibérica.

A ação censória da Inquisição portuguesa colocou o De re aedificatoria no Index expurgatoria de 1581 e a Inquisição espanhola no Index expurgatoria de 1584, o que dificultou a sua difusão. Com efeito, os exemplares em castelhano do De re aedificatoria que estão conservados em colecções particulares espanholas ou em bibliotecas públicas, como as de Santa Cruz de Valladolid ou da Biblioteca Nacional em Madrid, aparecem com páginas inteiras rasuradas, nomeadamente as relacionadas com a distribuição e a organização dos altares nos templos ${ }^{676}$. Também os exemplares que se conservam nas bibliotecas portuguesas, como a edição de Francisco Lozano ${ }^{677}$ existente no Departamento de Matemática da Faculdade e Ciências e Tecnologia da Universidade de Coimbra, se apresentam com este passo riscado (Fig.3):

673 ANTONIO DE NEBRIJA, Gramática sobre la lengua castellana, 1492. Ed. lit. de Carmen Lozano, 2011. Madrid, Real Academia Española.

674 Apud PABlO JAURAlde POU, Francisco Quevedo. Madrid, Castalia, 1998, p. 614.

675 Cf. CECIL GRAYSON, "La Prima Edizione del 'Philodoxeos'”, Rinascimento, 1954, vol. 5, 1, pp. 291- 293.

676 Cf. JAVIER RIVERA, Prólogo. De re aedificatoria. Trad. esp. de J. F. Núñez. Madrid, Ediciones Akal, S.A., 1991, p. 48.

677 FRANCISCO LOZANO, De Re Aedificatoria ó Los Diez Libros de Arquitetura de Leon Baptista Alberto, traduzido de Latim em Romance. Madrid, Alonso Gómez. 1582, p. 221. 
Succedieron eftos tiēpos enlos quales pluguieffe a Dios que fe leuantaffe algun hombre graue (có paz delos pontifices) que tuuieffe por bien emendarlos. Los quales como por caufa de cốferuar la dignidad apeñas vna vez enel año fe dexã ver al pueblo, lohi zieron todo tan lleno de altares, no digo mas, fino affirmo, que acerca delos hombres ninguna cofa fe puede hallar ni penfar que fea mas digna o iancta, $\bar{q}$ el facrificio. Y creo que no aura ningun fabio que quiera que las colas dignas fe hagan viles con la mucha abundācia.

("Seguiram-se os nossos tempos, que oxalá nenhum homem sério, sem ofensa para os bispos, considerasse dignos de serem censurados: como, para salvaguardar a sua dignidade, eles concedem ao povo a possibilidade de os verem apenas nas calendas do princípio do ano, a tal ponto encheram tudo de altares e às vezes $\langle\cdots\rangle$ não digo mais. Isto afirmo: entre os mortais, nada se pode encontrar e nem sequer imaginar, que seja mais condigno e mais santo do que o sacrifício. Eu, porém, julgo que não é tido por sensato ninguém que queira que as coisas mais dignas se banalizem, postas à disposição com excessiva facilidade" $)^{678}$.

678 LEON BATTISTA ALBERTI, Da Arte Edificatória, Tradução, notas e revisão disciplinar de Mário Krüger, tradução de A. M. do Espírito Santo, Lisboa, Fundação Calouste Gulbenkian, 2011, Livro VII, cap. 13. 


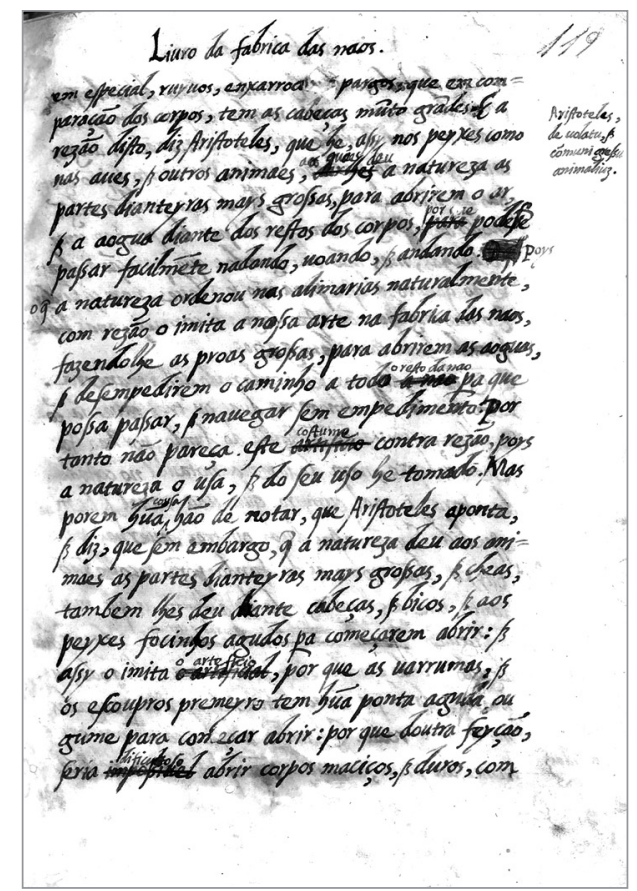

Fig. 3 - Liuro da Fabrica das Naos de Fernão de Oliveira (1580, p. 119), onde se pode ler a relação nau-corpo animal ${ }^{679}$.

Este corte sugere, apesar de Alberti ser moderado nas observações que faz ao colocar textualmente de his actenus 680 ("não digo mais"), não foi do agrado das autoridades inquisitoriais face à crítica aos bispos da igreja, por encherem as igrejas de altares aos santos, i.e. aos deuses menores, sob pena de se banalizarem as "coisas mais dignas".

679 "Os peixes, que são exemplo dos navios, os mais deles têm as partes dianteiras mais grossas que as de trás, em especial, ruivos, enxarrocos e pargos, que em comparação dos corpos, têm as cabeças muito grandes e a razão disto, diz Aristóteles, que é, assim nos peixes como nas aves, e noutros animais, aos quais deu a natureza as partes dianteiras mais grossas, para abrirem o ar e a água diante dos restos dos corpos, por se poder passar facilmente nadando, voando, e andando, por o que a natureza ordenou nas alimárias naturalmente, com razão o imita a nossa arte na fábrica das naus, fazendo-lhe as proas grossas, para abrirem as águas, e desimpedirem o caminho a todo o resto da nau para que possa passar, e navegar sem impedimento, portanto não pareça este costume contra razão, pois a natureza o usa, e do seu uso é tomado".

680 LEON BATTISTA ALBERTI, L'Architettura -De re aedificatoria, Intr. e notas de P. Porthoguesi, edição de texto em latim e trad. para it. de G. Orlandi,1966. Milão, Il Polifilio. 
De igual modo, a edição de Eufrosina de Jorge Ferreira de Vasconcelos, à semelhança do tratado de Alberti, constou do Index da Inquisição Portuguesa, pelo menos de 1581 a 1612.

É provável que Ferreira de Vasconcelos estivesse a par de mais obras de Alberti, nomeadamente da peça satírica Momus, o deus da crítica mordaz e da discórdia, dado que na Comedia Aulegrafia Vasconcelos introduz um personagem que se apresenta como “... hum dos antigos Deoses, que por nome não perca, o Momo"681.

Com efeito, o reparo crítico ao programa de melhoramentos da cidade de Roma do Papa Nicolau V, implicitamente desenvolvido na peça Momus, onde Alberti ${ }^{682}$ denuncia os comportamentos do fraco príncipe, i.e. do Papa, e da sua ambiciosa corte, pode ser cotejado com a Comedia Aulegrafia de Ferreira de Vasconcelos, onde o ambiente cortesão se transformou num lugar algo perturbador, incerto e paradoxal e as suas personagens, à semelhança da cúria papal, viviam da ganância, insídia e impostura.

Tanto a comédia Pbilodoxeos fabula, já tinha sido publicada em Salamanca em $1500^{683}$, como em 1553 a primeira tradução em castelhano da versão latina do Momus de Alberti, sob o título La moral y muy graciosa historia del Momo ${ }^{684}$, é impressa em Alcalá de Henares e reeditada no final do século, o que sugere que estas obras provavelmente circulavam, com alguma censura inquisitorial, no espaço ibérico sob o domínio dos Austrias.

Por outro lado, Mateus do Couto-o-Velho desempenhou, a partir de 1616, diversos cargos oficiais, nomeadamente o de arquiteto do tribunal

681 JORGE FERREIRA VASCONCELOS, Comédia Aulegrafia. Prefácio, notas e glossário de A. A. M. Vilhena, $2^{\text {a }}$ ed., 1969, Porto, 1:v14-15; Cf. SILVINA MARTINS PEREIRA, Tras a nevoa vem o sol. As comédias de Jorge Ferreira de Vasconcelos. Tese de Doutoramento. Versão revista em 2010. Faculdade de Letras. Universidade de Lisboa, 2009, pp. 283 - 284, 513 - 514.

682 LEON BATTISTA ALBERTI, Momus, 1437, Trad. ingl. de S. Knight. Texto em latim editado por V. Brown - S. Knight, 2003. Londres, Harvard University Press, IV.

683 Cf. MARIÀngela VIlallongA, "Quid Tum. La Perviviencia Hispânica de Leon Battista Alberti en dos Traducciones Catalanas”, in R. Cardini - M. Regoliosi, org., Leon Battista Alberti Umanista e Scrittore. Filologia, Esegesi, Tradizione. Florença, Edizioni Polistampa, 2007, pp. 755.

${ }^{684}$ LEON BATTISTA ALBERTI, La moral y muy graciosa historia del Momo, 1553. Trad. de J. De Mey, Alcalá de Henares. 
do Santo Ofício em $1634^{685}$, o que se configura como uma situação conflituosa dada as suas explícitas preferências pelo tratado de Alberti, conforme regista no seu Tractado De Architectura, publicado em 1631.

A implantação da ação sensória da Inquisição em Portugal teve efeitos que vão para além da simples proibição de circulação destas obras na Península Ibérica. Na verdade, toda uma geração de humanistas foi silenciada, tendo os seus efeitos perdurado por vários séculos.

Cite-se, entre outros casos, de alguma forma relacionados com a arte edificatória, a proibição da obra de Damião de Góis (1502-1574), Urbis Olisiponis descriptio, publicada em 1554 em Évora686, que faz uma descrição dos edifícios notáveis de Lisboa e cujo autor foi acusado de luteranismo, tendo posteriormente falecido em circunstâncias misteriosas, bem como de Fernão de Oliveira (1507- c.1581) que escreveu a Grammatica da Lingoagem Portuguesa ${ }^{687}$, publicada em 1536, e acabou por ser denunciado em 1547 ao Santo Ofício pelo seu antigo professor em Évora, o mestre André de Resende, sendo em consequência disso preso por quatro anos ${ }^{688}$.

Fernão de Oliveira, à semelhança de João Baptista Lavanha, é também o autor de um tratado sobre construção naval, o Liuro da Fabrica das Naos, redigido sob a forma de manuscrito em 1580, mas somente

685 Cf. HORÁCIO MANUEl PEREIRA BONIFÁCIO, "Mateus do Couto (tio)", in J. F. Pereira (dir.) e P. Pereira (coord.), Dicionário da Arte Barroca em Portugal. Lisboa, Editorial Presença, 1989, pp. 142-143.

686 DAMIÃO DE GÓIS, Vrbis Olisiponis descriptio per Damianum Goem equitem lusitanum, in qua obiter tractantur nõ nulla de indica nauigatione, per graecos et poenos et lusitanos, diuersis temporibus inculcata, 1554, Andream Burge[n]sem, Évora.

687 FERNÃO DE OLIVEIRA, Grammatica da lingoagem portuguesa, 1536, Lisboa, Germão Galharde.

688 A partir de 1541 André de Resende torna-se consultor do Santo Ofício em Évora, ainda quando este tribunal não estava inteiramente implantado no reino, defendendo uma inflexível ortodoxia que contribuiu para a condenação de réus acusados de heresia. Cf. HUGO MIGUEL CRESPO, "André de Resende na Inquisição de Évora e a apologética anti-judaica: ciência teológica, doutrina e castigo (1541). Um autógrafo inédito (Novos documentos para as biografias de André de Resende e Jorge Coelho)". In Humanismo, Diáspora e Ciência (séculos XVI e XVII): estudos, catálogo, exposição, 2013. Org. CMP/ Biblioteca Pública Municipal do Porto e UA/Centro de Línguas e Culturas, pp.151-212; ANDRÉ DE RESENDE, Obras Portuguesas. Prefácio e notas de J. P. Tavares, 1963. Lisboa, Livraria Sá da Costa Editora; MARIA LEONOR CARVALHÃO BUESCU "A primeira anotação da língua portuguesa”, 1988, Revista FCSH, pp. 59-74. 
publicado em 1889 por Henrique Lopes de Mendonça ${ }^{689}$, o que nos faz supor que alguma forma de censura implícita se exerceu sobre esta obra, devido aos antecedentes do seu autor junto ao Santo Ofício.

Este manuscrito configura-se como o mais antigo tratado peninsular em que a construção naval, em estreita afinidade com o autor do De re aedificatoria, deixa de estar vinculada aos mestres construtores das ribeiras e passa a ser do domínio teórico pela geometrização das formas e a modelação das suas estruturas. Além disso, Fernão de Oliveira também assume a analogia nau-corpo animal, o que é igualmente evocativo da relação edifício-corpo de Alberti (Ver Fig. 3) ${ }^{690}$.

Note-se, ainda, que Fernão de Oliveira caracteriza o navio por uma noção afim da concinidade albertiana visto que o define como "aquelle que tem feyção formada por certas medidas, pellas quaes tem suas partes concertadas hũas com outras, com deuida proporção, \& conueniencia" ${ }^{691}$. Na verdade, para Alberti ${ }^{692}$, “... são três as principais noções em que se condensa na totalidade aquele princípio que buscamos: número, aquilo a que chamamos delimitação, e disposição. Mas há qualquer coisa mais em virtude da qual, a partir da junção e ligação dessas três noções, resplandece maravilhosamente toda a face da beleza: e nós dar-lhe-emos a designação de concinidade".

Em síntese, o tratado de Fernão de Oliveira, pela geometrização das formas e modelação matemática das suas estruturas, pela relação nau-corpo animal e pela concertação das suas partes, situa-se nos domínios da construção naval muito próximo dos conceitos desenvolvidos por Alberti no seu tratado sobre a arte edificatória.

No entanto, os resultados das ações persecutórias do Santo Ofício não se abateram apenas sobre estes autores e as suas circunstâncias, mas

689 HENRIQUE LOPES DE MENDONÇA, O padre Fernando de Oliveira e a sua obra náutica. Memória compreendendo um estudo biográfico sobre o afamado gramático e nautógrafo e a primeira reprodução tipográfica do seu trabalbo inédito Livro da Fábrica das Naus, 1898. Lisboa, Academia Real das Ciências.

690 LEON BATTISTA AlBERTi, Da Arte Edificatória. Trad. A. E. Santo, introd., notas e revisão disciplinar de M. J. T. Krüger, 2011. Lisboa, Fundação Calouste Gulbenkian.

${ }^{691}$ FERNÃO DE OLIVEIRA, O Livro da Fábrica das Naus. Lisboa, Academia da Marinha, 1580/1991, p. 75.

692 LEON BATTISTA ALBERTI, op. cit., Livro IX, cap. 5. 
tiveram efeitos que se prolongaram em tempo longo. A Comédia Eufrosina de Jorge Ferreira de Vasconcelos somente vai à cena em Lisboa em 1998, com adaptação de Silvina Pereira e Rosário Laureano dos Santos, e o tratado de Alberti é primeiramente publicado em 2011, em Lisboa, com o título Da Arte Edificatória, com tradução de Arnaldo Monteiro do Espírito Santo e introdução, notas e revisão disciplinar de Mário Júlio Teixeira Krüger.

Neste contexto, algo tumultuoso, em que ocorre a receção inicial ao tratado de Alberti, é pertinente recapitular o que Jauss ${ }^{693}$ designa por "horizonte de espera" (erwartunshorizont), na estética da receção de obras literárias, para significar o diálogo crítico entre o público e a obra, onde aquele não é compreendido somente como um leitor passivo, mas como sujeito de uma apropriação ativa, que modifica o seu sentido, desde a sua publicação até ao momento presente.

Assim, podemos afirmar que a presumível tradução de André de Resende configura um "horizonte de perda”, em termos da evolução da compreensão da arquitetura em Portugal nos últimos cinco séculos, principalmente pela ausência de uma receção explícita àquela obra que a privou de um discurso comentador nas fases iniciais da receção ao tratado de Alberti.

Resta-nos afortunadamente a obra edificada em Portugal, principalmente as relacionadas com os edifícios dedicados ao culto religioso, que apresentam um cunho vincadamente albertiano e que são uma fonte insubstituível para a compreensão da influência deste autor no período da Contra-Reforma em Portugal.

Cabe citar a este propósito a igreja de São Vicente de Fora em Lisboa que, além de se apresentar com uma nave abobadada em forma de berço e com caixotões, exibe três tramos com capelas laterais e vãos intermédios precedidos de um nartex porticado, combinados com pares de pilastras duplas o que, no seu conjunto, é evocativo da solução apresentada por Alberti para o interior da igreja de Santo André em Mântua.

693 HANS ROBERT JAUSS, Pour une esthétique de la recéption, 1978, Trad. fr. de Cl. Maillard. Paris, Editions de Minuit. 
Além disso, a definição de basílica para Alberti ${ }^{694}$ refere-se a um edifício onde os cidadãos se reuniam para administrar justiça, constituída por um espaço amplo e transitável acrescentado, por vezes, de uma nave transversal designada de "causídica" visto aí se movimentavam os oradores e os advogados.

Dado que a nave causídica forma um falso transepto em vez de uma cruz latina, isso significa que Alberti não assume integralmente o simbolismo religioso da iconografia cristã mas das basílicas pagãs, à semelhança do que se verifica integralmente em São Vicente de Fora, o que sugere uma plena adesão, sob o ponto de vista de organização espacial, aos princípios sugeridos no De re aedificatoria.

Se bem que os debuxos iniciais da igreja de S. Vicente de Fora em Lisboa sejam, provavelmente, de autoria de Juan Herrera, que esteve em Lisboa entre 1581 e 1583, o equivalente ao que entendemos, atual e aproximadamente, por projeto de execução foi elaborado, ainda no séc. XVI por Filippo Terzi, bem como mais tarde por Leonardo Torriano, Baltazar Álvares, Pedro Nunes Tinoco e João Nunes Tinoco nos sécs. XVI - XVII ${ }^{695}$.

Em 1582 dá-se a demolição do primitivo edifício e o início da edificação da nova igreja, segundo projeto de Filippo Terzi, e a 28 de agosto de 1629 é celebrada na igreja a $1^{\text {a }}$ missa.

Em resumo, os arquitetos responsáveis pelo projeto e obra da igreja de São Vicente de Fora, que irá servir de matriz referencial para os edifícios do culto religioso durante a Contra-Reforma, tanto em Portugal como nos territórios do ultramar, ficaram a partir do início da sua construção com a possibilidade de consultar o tratado de Alberti, cuja tradução foi assistida por Francisco Lozano para castelhano, mas não para a língua portuguesa.

${ }^{694}$ LEON BATTISTA ALBERTI, op. cit., Livro VII. cap. 14.

695 Cf. A. CRISTINA LOURENÇO, MIGUEL SOROMENHO - F. S. MENDES, "Filipe II en Lisboa: Moldear la Ciudad a la Imagen del Rey", in P. B. Pereira, org., Juan de Herrera, Arquiteto Real. Barcelona: Lunwerg Editores, 1997, p. 129; MIGUEL ÁNGEL, ARAMBURU-ZABAlA HigUERA, CELESTINA LOSADA VAREA, ANA CAGIGAS ABERASTURI, Biografia de Juan de Herrera. Santander: Fundación Obra Pía Juan de Herrera, 2003, p.299; CARLOS RUÃO, "O Eupalinos Moderno". Teoria e Prática da Arquitetura Religiosa em Portugal (1550-1640). 3 vols. Tese de Doutoramento. Coimbra, Faculdade de Letras da Universidade de Coimbra, 2006, Vol. II, pp. $60-62$. 

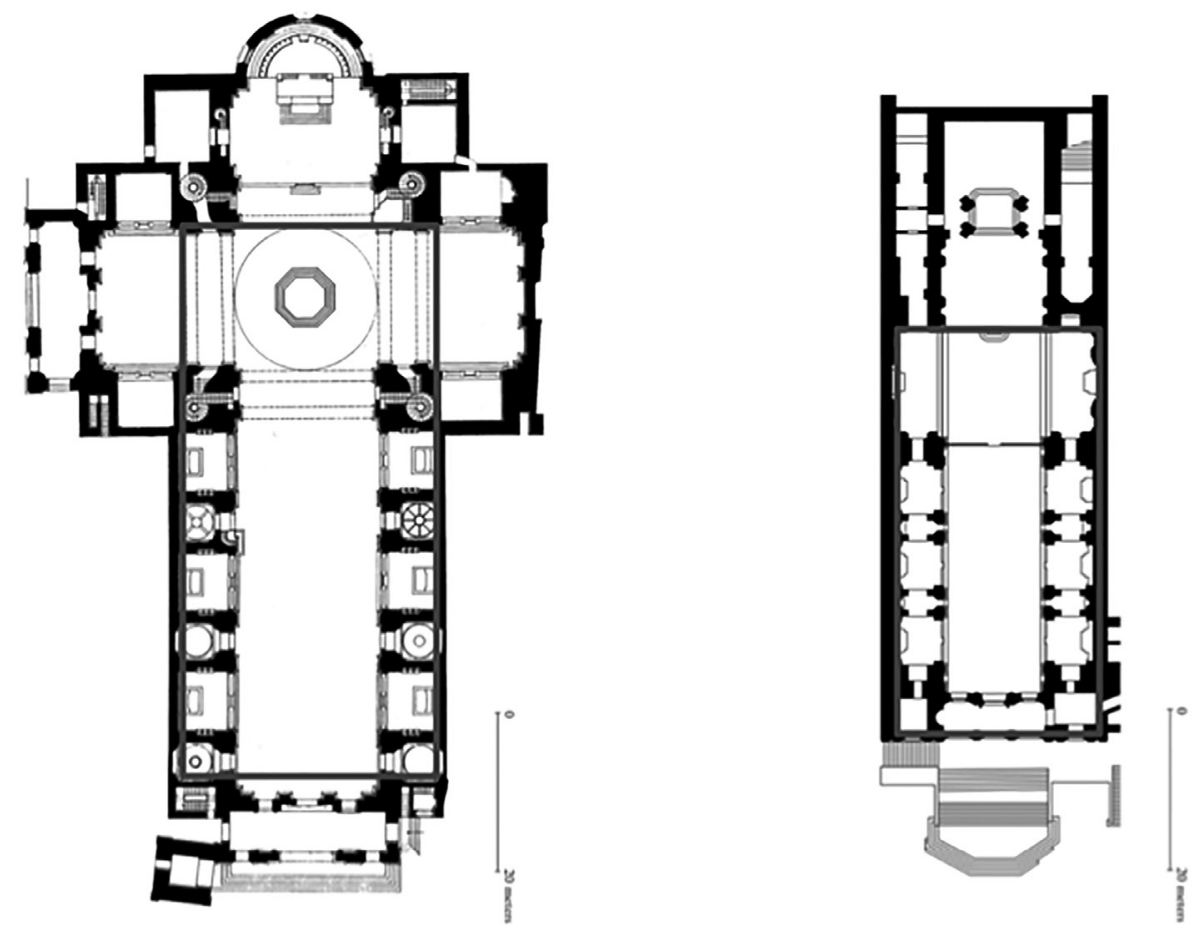

Fig. 4 - Plantas, à mesma escala, das igrejas de Sant'Andrea em Mântua de Leon Battista Alberti, parcialmente concluída em 1470, e de São Vicente de Fora, em Lisboa, iniciada em 1582 sob a orientação inicial de Juan de Herrera e de Filippo Terzi.

As obras desaparecidas que têm povoado a história da arte e da arquitetura poderiam ser uma das fontes para reconstruir o que um dia eventualmente existiu ou poderá ter existido, como sucede com a eventual tradução de André de Resende do tratado de Alberti como, noutro contexto, com as obras perdidas do pintor Apeles, na Grécia antiga.

Alberti expõe textualmente a descrição de Luciano (Calumniae non temere credendum) ${ }^{696}$ sobre uma pintura de Apeles, a Calúnia, que remata com uma pertinente questão: "Se esta história enche a imaginação quando

696 LUCIANO (1972-1974) Luciani Opera. Org. de M. D. Macleod. Oxford, Clarendon Press, $1^{\circ}$ e $2^{\circ}$ vols. 
é descrita por palavras, quanta beleza e prazer pensas que apresentaria a verdadeira pintura pela mão de Apeles?"697

Em síntese, esta é a relevância, como procurámos mostrar ao longo deste artigo, da herança disciplinar do De re aedificatoria na arquitetura clássica em Portugal.

Nota Final: Este trabalho é resultante do projeto de investigação "Digital Alberti", desenvolvido no Centro de Estudos Sociais da Universidade de Coimbra e financiado pela Fundação para a Ciência e Tecnologia (FCT), no âmbito do COMPETE/FEDER, Portugal (PTDC/AUR - AQI/108274/2008).

697 LEON BATTISTA ALBERTI, De pictura, 1441-1444, Org. de C. Grayson, 1980. Bari, Laterza, III, 53, "Quae plane historia etiam si dum recitatur animos tenet, quantum censes eam gratiae et amoenitatis ex ipsa pictura eximii pictoris exhibuisse?" 